\title{
TECNOLOGIAS DE INFORMAÇÃO E COMUNICAÇÃO: PERCEPÇÃO DE DIRETORES E PROFESSORES
}

\author{
FÁtIMA APARECIDA MEDICI ${ }^{1}$ \\ TÂNIA BARBOSA MARTINS ${ }^{2}$
}

\begin{abstract}
RESUMO: $\mathrm{O}$ artigo trata da percepção dos diretores e professores sobre as Tecnologias de Informação e Comunicação (TICS) no processo educacional, tendo como referência o conjunto de ações e programas governamentais criados na rede estadual paulista de ensino. $O$ estudo se pauta na metodologia qualitativa e realização de entrevistas em três escolas da rede estadual paulista, numa cidade interiorana. Apresenta-se o arcabouço legal relacionado ao uso das tecnologias na educação, mostram-se os programas de tecnologia e, finalmente, as concepções dos diretores e professores das escolas estaduais. Conclui-se que, embora aparentemente a política seja de incentivo ao uso das TICs, há limites em relação à formação e condições objetivas para seu uso na educação.

Palavras-chave: Política Educacional. Tecnologia Educacional. Tecnologias de Informação e Comunicação.
\end{abstract}

INFORMATION AND COMMUNICATION TECHNOLOGY: PERCEPTION OF THE PRINCIPALS AND TEACHERS

ABSTRACT: The article analyzes the perception of the principals and teachers about Information and Communication Technologies (ICTs) in the educational process, having as reference the set of actions and governmental programs created in the state of São Paulo. The study is based on the qualitative methodology and interviews in three schools of the state of São Paulo, in an interior city. It presents the legal framework relating to the use of technologies in education, a discussion about the technology programs and finally, the conceptions of the principals and teachers of the state schools. It is concluded that although the policy appears to be an incentive to use ICTs, there are limits regarding the qualification and objective conditions for the use of ICT in the education.

Keywords: Educational Policy. Educational Technology. Information and Communication Technologies.

1 Mestre em Educação pela Universidade Metodista de Piracicaba (UNIMEP).

2 Professora do Programa de Pós-Graduação em Educação (PPGE) da Universidade Metodista de Piracicaba (UNIMEP). 


\section{TECNOLOGÍAS DE INFORMACIÓN Y COMUNICACIÓN: PERCEPCIÓN DE DIRECTORES Y PROFESORES}

RESUMEN: El artículo trata de la percepción de los directores y profesores sobre las Tecnologías de Información y Comunicación (TICS) en el proceso educativo, teniendo como referencia el conjunto de acciones y programas gubernamentales creados en la red estadual paulista. El estudio se basa en la metodología cualitativa y realización de entrevistas en tres escuelas de la red estadual paulista de enseñanza, en una ciudad del interior. Presenta el marco legal en relación con el uso de las tecnologías en la educación, una discusión sobre los programas de tecnología en la red estadual paulista de enseñanza y las concepciones de los directores y profesores de las escuelas estatales. Se concluye que, aunque aparentemente la política es de incentivo al uso de las TIC, hay límites en relación a la formación y condiciones objetivas para el uso de las TICs en la enseñanza.

Palabras clave: Política Educativa. Tecnología Educativa. Tecnologías de Información y Comunicación.

\section{Introdução}

Com o ritmo acelerado do capitalismo e com os novos paradigmas de reestruturação produtiva, as Tecnologias de Informação e Comunicação (TICS) são utilizadas em vários ramos de atividades, abrangendo processos produtivos, financeiros e sociais. Segundo Ponte (2000, p. 64), as TICs se apresentam em três domínios distintos, embora integrados entre si: a) processamento, armazenamento e pesquisa de informação realizada pelo computador; b) controle e automatização de máquinas, ferramentas, processos e procedimentos; c) a organização, representação e comunicação da informação na forma de textos, imagens, sons e vídeos. Segundo Castells (1999, p. 51), a matériaprima essencial das TICs é a informação. O referido autor relata que "a sociedade em rede modifica de forma substancial a operação e os resultados dos processos produtivos e de experiência, poder e cultura" de tal modo que a identidade das pessoas está sendo modificada pelas sociedades organizadas em rede.

Apesar do conjunto de mudanças produzidas pelas TICs, há que destacar conforme Almeida e Valente $(2012$, p. 58) que há uma parcela significativa da população que se encontra excluída do acesso e utilização das tecnologias em seu cotidiano. Especificamente, a produção do conhecimento sobre as TICs na educação mostra que os recursos tecnológicos não são incorporados nos processos de ensino-aprendizado como possibilidades efetivas de aprendizagem. Em conformidade, Rosa (2013) relata que os professores possuem muitas dificuldades técnicas e de manuseio em relação aos equipamentos. Disso decorre a necessidade de uma ressignificação dos recursos tecnológicos, de maneira especial, nos cursos de formação de professores. 
As TICs na educação adquirem importância legal a partir dos anos de 1990, especialmente na Lei de Diretrizes e Bases da Educação Nacional (LDB), no. 9.394, de 26 de dezembro de 1996 (BRASIL, 1996). A partir daí um conjunto de prerrogativas legais foram produzidas com destaque nas Diretrizes Curriculares Nacionais da Educação Básica de 2013 e no Plano Nacional de Educação (PNE), aprovado pela Lei $n$ o 13.005 , de 24 de junho de 2014.

Há ainda várias ações e programas que visam o uso das TICs na educação criados pelos governos federais e estaduais. Especificamente, o governo estadual de São Paulo, seguindo a dianteira da tendência, inseriu programas e ações que preconizam o uso das TICs nos processos educativos e no trabalho administrativo nas escolas. Nos últimos dez anos, destacam-se: Programa Acessa Escola; Escola Virtual de Programas Educacionais (EVESP); Núcleo de Informações Educacionais e Tecnologia (NIT); Plataforma Currículo+; Projeto Aventura Currículo+; e Plataforma GeekieLab+. Esse conjunto de ações e de programas materializam no Estado as políticas nacionais de incentivo às TICs (CARVALHO, 2015; KLEINE; NACARATO, 2016; LIRA, 2014; MAGNONO; SILVA, 2014; MONTEIRO, 2005).

Apesar da introdução das TICs no arcabouço legal e do conjunto de ações e programas de incentivo ao uso das TICs no processo educacional, pouco se sabe sobre seus impactos reais, positivos e/ou negativos, no cotidiano da educação estadual e, particularmente, sobre as condições objetivas nas escolas que visam assegurar o uso consistente dos recursos tecnológicos. $\mathrm{O}$ artigo tem como objetivo apresentar resultados de uma investigação que buscou compreender as políticas de tecnologia, informação e comunicação da rede estadual paulista de ensino, considerando as concepções e percepções dos diretores e professores de três escolas da rede estadual, de uma cidade localizada no interior do Estado de São Paulo.

\section{O Incentivo ao uso das tecnologias no arcabouço legal}

A mundialização econômica produziu uma nova fase de estruturação e institucionalização da educação brasileira a partir de meados da década de 1990, sendo possível reconhecer uma nova regulamentação das políticas educacionais com repercussões diretas no sistema nacional público de ensino. Nesse contexto, as TICs vêm adquirindo importância no delineamento da legislação educacional, de maneira especial, na LDB no 9.394/96, nos artigos 32 e 36, as TICs se apresentam relacionadas à formação básica do cidadão:

[...] Art. 32 - O ensino fundamental obrigatório, com duração de 9 (nove) anos, 
gratuito na escola pública, iniciando-se aos 6 (seis) anos de idade, terá por objetivo a formação básica do cidadão, mediante: [...] II - a compreensão do ambiente natural e social, do sistema político, da tecnologia, das artes e dos valores em que se fundamenta a sociedade (BRASIL, 1996)

Art. 36 - O currículo do ensino médio observará o disposto na Seção I deste Capítulo e as seguintes diretrizes: I - destacará a educação tecnológica básica, a compreensão do significado da ciência, das letras e das artes; o processo histórico de transformação da sociedade e da cultura; a língua portuguesa como instrumento de comunicação, acesso ao conhecimento e exercício da cidadania; [...] § 1응 Os conteúdos, as metodologias e as formas de avaliação serão organizados de tal forma que, ao final do ensino médio, o educando demonstre: I - domínio dos princípios científicos e tecnológicos que presidem a produção moderna (BRASIL, 1996).

Tendo em vista o incentivo da LDB no 9.394/96 ao uso das TICs no processo educacional, as Diretrizes Curriculares Nacionais da Educação Básica consolidam por sua vez a necessidade da integração, mediada e mesmo direta, das TICs na educação e nas escolas. As Diretrizes Curriculares recomendam a necessidade de se assegurar uma infraestrutura tecnológica nas escolas com "o acesso dos estudantes à biblioteca, ao rádio, à televisão, à internet aberta às possibilidades da convergência digital" (BRASIL, 2013, p. 25). As Diretrizes Curriculares defendem que a escola precisa acolher diferentes saberes e manifestações e se empenhar para se constituir, ao mesmo tempo, em um espaço de diversidades e acolhimento das novas tecnologias da informação e comunicação. Além disso, advoga a necessidade de construção de um novo paradigma educacional em que as TICs sejam centrais tanto na institucionalidade escolar quanto no processo de ensino-aprendizagem.

\footnotetext{
O impacto das novas tecnologias sobre as escolas afeta tanto os meios a serem utilizados nas instituições educativas, quanto os elementos do processo educativo, tais como a valorização da ideia da instituição escolar como centro do conhecimento; a transformação das infraestruturas; a modificação dos papéis do professor e do aluno; a influência sobre os modelos de organização e gestão; o surgimento de novas figuras e instituições no contexto educativo; e a influência sobre metodologias, estratégias e instrumentos de avaliação (BRASIL, 2013, p. 163).
}

As Diretrizes Curriculares contemplam a inserção das TICs dentro de seus princípios, fundamentos e procedimentos, orientando as escolas para a necessidade de uma nova organização, articulação, desenvolvimento e avaliação de suas propostas pedagógicas. Há que destacar que, nos últimos anos, as TICs foram contempladas também no Documento Final da Conferência Nacional de Educação (CONAE), cujas considerações serviram de parâmetro para a elaboração das Metas e 
estratégias de ação do Plano Nacional de Educação (PNE) 2014-2024. No Documento-Referência da CONAE (2014) é evidente o estímulo à presença de práticas educacionais que possibilitam o desenvolvimento de:

[...] tecnologias educacionais e recursos pedagógicos apropriados ao processo de aprendizagem, laboratórios de informática, pesquisa on-line e intercâmbio científico e tecnológico, nacional e internacional, entre instituições de ensino, pesquisa e extensão (CONAE, 2014, p. 32).

O Documento-Referência consolidou valores e posições referentes aos aspectos culturais, políticos e econômicos, apontando novas perspectivas para a organização da educação nacional no novo PNE, notadamente no que diz respeito à "[...] construção de novas estratégias pedagógicas, à produção de materiais didáticos e à implementação de novas metodologias e tecnologias educacionais" (CONAE, 2014, p. 35).

A educação é uma prática social cada vez mais ampla e presente na sociedade contemporânea, pois vêm-se multiplicando os ambientes e processos de aprendizagem formais e informais, envolvendo práticas pedagógicas e formativas em instituições educativas, no trabalho, nas mídias, nos espaços de organização coletiva, potencializados pelas tecnologias de comunicação e informação (CONAE, 2014, p. 40).

No Documento-Referência há ainda uma série de considerações sobre a importância do aumento da chamada educação tecnológica, especialmente no estímulo à existência dos laboratórios de informática, pesquisas on-line e intercâmbios científicos e tecnológicos, nacionais e internacionais, entre instituições de ensino, pesquisa e extensão. O Documento-Referência enfatiza:

[...] o desenvolvimento de competências e habilidades para o uso das tecnologias de informação e comunicação (TIC) na formação inicial e continuada dos/das profissionais da educação, na perspectiva de transformação da prática pedagógica e da ampliação do capital cultural dos/das professores/as e estudantes (CONAE, 2014, p. 81).

Em conformidade na Lei 13.005, de 25 de junho de 2014, que implantou o PNE 2014-2024, observa-se que das vinte Metas, oito são estratégias que apontam as TICs como centrais no processo de articulação e mediação da qualidade do ensino e formação dos educadores. De modo geral, as Metas e estratégias do PNE colocam as TICs no mesmo patamar que outras relevantes e importantes questões educacionais, como a alfabetização das crianças, a melhoria do nível de aprendizado ao longo da educação básica, o atendimento às populações do campo, a preocupação com a educação de 
mulheres negras e mais pobres, a democratização do acesso à educação superior, a formação de professores, dentre outros.

Nessa perspectiva, em relação à Meta 3 do PNE, que se refere à universalização da educação básica, a estratégia preconiza a institucionalização de programas de renovação do ensino articulados a várias dimensões que incluem a tecnologia. Em se tratando da alfabetização de crianças, a Meta 5 assinala que todas as crianças até o final do 3 으 ano do ensino fundamental devem ser alfabetizadas. Para atingir essa Meta, o processo educacional deve considerar a diversidade de métodos e propostas pedagógicas, inclusive, na formação de professores (BRASIL, 2014).

No que se refere à qualidade da educação básica em todas as etapas e modalidades, a Meta 7 também preconiza as tecnologias como necessárias no alcance do nível suficiente de aprendizado em relação às médias nacionais previstas para o índice de desenvolvimento para a educação básica (IDEB):

\begin{abstract}
Meta 7: Fomentar a qualidade da educação básica em todas as etapas e modalidades, com melhoria do fluxo escolar e da aprendizagem de modo a atingir as seguintes médias nacionais para o Ideb [...]. Estratégia: 7.12) incentivar o desenvolvimento, selecionar, certificar e divulgar tecnologias educacionais para a educação infantil, o ensino fundamental e o ensino médio e incentivar práticas pedagógicas inovadoras que assegurem a melhoria do fluxo escolar e a aprendizagem, asseguradas a diversidade de métodos e propostas pedagógicas, com preferência para softwares livres e recursos educacionais abertos, bem como o acompanhamento dos resultados nos sistemas de ensino em que forem aplicadas; [...]. Estratégia: 7.15) universalizar, até o quinto ano de vigência deste PNE, o acesso à rede mundial de computadores em banda larga de alta velocidade e triplicar, até o final da década, a relação computador/aluno (a) nas escolas da rede pública de educação básica, promovendo a utilização pedagógica das tecnologias da informação e da comunicação (BRASIL, 2014).
\end{abstract}

A Meta 8 apresenta o desenvolvimento de tecnologias para correção de fluxo, para acompanhamento pedagógico individualizado, recuperação e progressão parcial da população de dezoito a vinte e nove anos, especificamente, das populações do campo, negras e mais pobres.

[...] Institucionalizar programas e desenvolver tecnologias para correção de fluxo, para acompanhamento pedagógico individualizado e para recuperação e progressão parcial, bem como priorizar estudantes com rendimento escolar defasado, considerando as especificidades dos segmentos populacionais considerados (BRASIL, 2014). 
Na mesma direção que focaliza uma série de problemas a uma solução mediada pela tecnologia, as Metas 9 e 10 têm como objetivo a superação do analfabetismo entre os jovens com 15 anos ou mais anos de idade, adultos e idosos. A Meta 9 especificamente recomenda a promoção de programas e ações de capacitação tecnológica para jovens e adultos e, especialmente, voltados para a inclusão social e produtiva dessa população, isto é, a tecnologia, inclusive, como aporte e como formação profissional.

Meta 9: Elevar a taxa de alfabetização da população com 15 (quinze) anos ou mais para 93,5\% (noventa e três inteiros e cinco décimos por cento) até 2015 e, até o final da vigência deste PNE, erradicar o analfabetismo absoluto e reduzir em $50 \%$ (cinquenta por cento) a taxa de analfabetismo funcional. [...]. 9.11) implementar programas de capacitação tecnológica da população jovem e adulta, direcionados para os segmentos com baixos níveis de escolarização formal e para os (as) alunos (as) com deficiência, articulando os sistemas de ensino, a Rede Federal de Educação Profissional, Científica e Tecnológica, as universidades, as cooperativas e as associações, por meio de ações de extensão desenvolvidas em centros vocacionais tecnológicos, com tecnologias assistivas que favoreçam a efetiva inclusão social e produtiva dessa população (BRASIL, 2014).

A Meta 12 expressa a democratização do acesso à educação superior, com inclusão e qualidade, porém o salto projetado por esta Meta, que define a elevação da taxa bruta de matrícula para $50 \%$ e da líquida para 33\%, se revela extremamente desafiador, pois a garantia de uma educação de qualidade e a ampliação e democratização do acesso não se reduzem a simples oferta de vagas e muito menos ao fortalecimento de redes físicas de laboratórios tecnológicos, conforme estratégia apresentada na Meta 12, sobretudo, num país campeão no aspecto da desigualdade social. A democratização à educação ainda se apresenta como um direito em processo de consolidação (CARVALHO, 2004).

A formação acadêmica do professor em nível universitário, como requisito indispensável ao exercício docente, é proposta da Meta 15. Para que essa meta se concretize, a estratégia 15.6 destaca a importância da reforma curricular dos cursos de licenciatura bem como a incorporação das modernas tecnologias de informação e comunicação como um dos estímulos da renovação pedagógica.

Promover a reforma curricular dos cursos de licenciatura e estimular a renovação pedagógica, de forma a assegurar o foco no aprendizado do (a) aluno (a), dividindo a carga horária em formação geral, formação na área do saber e didática específica, incorporando as modernas tecnologias de informação e comunicação, em articulação com a base nacional comum dos 
currículos da educação básica, de que tratam as estratégias 2.1, 2.2, 3.2 e 3.3 deste PNE (BRASIL, 2014).

No PNE, as TICs são abordadas de maneira articulada com todos os atores da escola e em todos os espaços pedagógicos. O maior desafio relacionado às estratégias é a maneira objetiva como as TICs devem ser implantadas e implementadas para realmente assegurar a universalização do ensino e estimular o efetivo aprendizado, desde a educação infantil, o ensino fundamental e médio até o ensino superior e a formação dos profissionais da educação, considerando as novas metodologias de ensino, materiais didáticos, equipamentos e recursos de tecnológicos.

Embora a legislação educacional relacione as TICs à qualidade da educação, há que ressaltar, conforme Dourado e Oliveira (2009), que a qualidade da educação é um fenômeno complexo, que abrange múltiplas dimensões, não pode ser entendido apenas por um reconhecimento da variedade e das quantidades mínimas de elementos indispensáveis ao desenvolvimento do processo de ensinoaprendizagem, nem ser apreendido sem tais elementos. Em outros termos, a qualidade da educação envolve dimensões extraescolar e intraescolar e, neste prisma, devem ser considerados os diferentes atores, a dinâmica pedagógica, ou seja, os processos de ensino-aprendizagem, os currículos, as expectativas de aprendizagem, a formação do professor, assim como os diversos fatores extraescolares que interferem direta ou indiretamente nos resultados educativos. Conforme Zuin (2010), a inserção das TICs no processo educacional exige uma reflexão profunda sobre a forma como as novas TICs definem os caminhos dos atuais processos de ensino e aprendizagem e da nova institucionalidade escolar numa sociedade fundada nas tecnologias.

\section{Os programas de tecnologia na rede estadual paulista de ensino}

O governo estadual de São Paulo nos últimos dez anos inseriu programas e ações nas escolas estaduais conduzidas pela Secretaria do Estado da Educação de São Paulo (SEE). Há que destacar que o Programa Nacional de Informática nas Escolas (PROINFO), criado pelo governo federal, apresenta-se com um marco na propagação das TICs no Brasil. O referido programa se desdobrou em diversos outros programas estaduais com a criação de projetos de incentivo às TICs nas escolas públicas. $O$ PROINFO, criado pela Portaria no 522/MEC, de 9 de abril de 1997, visa introduzir as TICs nas escolas públicas como uma espécie de suporte ao processo de ensino-aprendizagem. De acordo com Bonilla e Pretto (2011), até dezembro de 2010, o PROINFO havia instalado 63.546 laboratórios de informática nas escolas do país. Os autores destacam que, com base no Censo de Educação Básica de 2011, 
aproximadamente $40 \%$ das escolas públicas brasileiras contavam, em 2010, com laboratórios de informática e 43\% tinham acesso à internet. Segundo Bonilla e Pretto (2011), milhões de crianças e jovens têm o primeiro contato com o computador e a internet por meio dos laboratórios do PROINFO.

O Programa Acessa Escola do Governo do Estado de São Paulo, implantado pela Resolução do Estado de São Paulo SE no 37, de 25 de abril de 2008, e modificado pela Resolução do Estado de São Paulo SE no 39, de 10 de junho de 2011, apresenta como objetivo promover a inclusão digital e estimular o uso da internet para enriquecimento da formação cultural, intelectual e social. Segundo Monteiro (2015), o programa conta com um espaço físico nas escolas, com alocação de computadores conectados à internet para uso gratuito pela comunidade escolar da rede estadual paulista, sendo uma tentativa de permitir o contato com as TICs à população escolar economicamente menos privilegiada. Com a intenção de capacitar os professores da rede estadual, a Secretaria de Educação, em 2009, constituiu parceria com uma empresa estrangeira do ramo de informática (Fundação Intel) para oferecer cursos de capacitação tecnológica (MONTEIRO, 2015).

Segundo Monteiro (2015), o Acessa Escola conta com uma série de dificuldades na sua prática pedagógica, destacando as seguintes razões: sala não disponível; falta de preparo do pessoal; problemas de infraestrutura; tamanho e layout da sala; número insuficiente de computadores; baixa velocidade na conexão; e turmas numerosas. A referida autora relata que é necessário que a Secretaria de Educação verifique as reais condições do Acessa Escola, com vistas à implementação de novas ações que suprimam fatores que dificultam e inviabilizam a utilização do referido programa na prática pedagógica da escola.

A Escola Virtual de Programas Educacionais (EVESP) foi criada em 2011 no âmbito da Secretaria de Educação pelo Decreto do Estado de São Paulo no 57.011, de 23 de maio de 2011. Desenvolve programas e cursos com a finalidade de oferecer programas educacionais regulares, especiais e de capacitação, tendo como base o uso intensivo das TICs. Segundo a Secretaria de Educação, a EVESP deve auxiliar a Coordenadoria de Gestão da Educação Básica nas seguintes atribuições:

1. Implementação virtual do currículo prescrito elaborado, atualizado e normatizado na educação básica; 2. Propostas e inserção das diretrizes e normas pedagógicas para todos os atores sociais com acesso no ambiente digital; 3. Elaboração dos materiais específicos e recursos pedagógicos do currículo prescrito para acesso remoto, síncrono e assíncrono; 4. Avaliação e definição dos recursos computacionais e midiáticos para uso pedagógico na 
educação básica; 5. Gestão das ações educacionais na rede virtual; 6 . Dimensionamento e definição dos recursos pedagógicos estratégicos e procedimentais para o ambiente digital de aprendizagem; 7. Análise dos resultados e proposição de medidas para a correção de rumos e de aprimoramento do processo de acesso e de aprendizagem (SÃO PAULO, 2013).

Os cursos do EVESP são oferecidos na modalidade de educação a distância e oportuniza aos alunos, professores e diretores de escola o desenvolvimento de habilidades relacionadas às TICs. São oferecidos diversos cursos, entre os quais: curso de Inglês On-Line; curso de Espanhol on-line; curso de Libras on-line; Defesa Civil - A Aventura; cursinho pré-universitário; Robótica com Arduino; Khan Academy; Youtube Edu; Programaê; Detona no ENEM; EJA - mundo do trabalho; Aluno Monitor; e, IT Academy.

A gestão e a responsabilidade acadêmico-administrativa da EVESP estão a cargo da Secretaria de Educação, em parceria com a Universidade Virtual do Estado de São Paulo (UNIVESP). De acordo com Magnoni e Silva (2014), os cursos virtuais oferecidos pela EVESP demandam uma avaliação mais criteriosa. Para os autores, até o momento, a maioria dos programas da Evesp comprova que a iniciativa é bastante restrita quanto ao objetivo de integração da sala de aula tradicional com os ambientes das TICs, porque o curso é acessado somente pelo estudante em casa ou em outro ambiente distinto da sala de aula na escola.

O Núcleo de Informações Educacionais e Tecnologia (NIT) é um ambiente computacional, integra o Centro de Informações Educacionais e Gestão de Rede Escolar, das Diretorias de Ensino do Estado de São Paulo e é orientado pelo Departamento de Tecnologia de Sistemas e Inclusão Digital, que está vinculado à Coordenadoria de Informações, Monitoramento e Avaliação Educacional, dentro da estrutura organizacional da Secretaria de Educação, segundo o artigo 74 do Decreto do Estado de São Paulo no 57.141, de 18 de julho de 2011. O NIT é formado por uma equipe interdisciplinar de diretores técnicos e estagiários universitários e conta com as várias atribuições detalhadas pela Resolução SE do Estado de São Paulo no 58, de 4 de junho de 2012 (CARVALHO, 2015).

O Plataforma Currículo+, lançada em 2014, apresenta conteúdos digitais - vídeos, videoaulas, jogos, animações, simuladores e infográficos - articulados com o Currículo do Estado. Visa incentivar a utilização da tecnologia como recurso pedagógico para inspirar práticas inovadoras na escola (professores e diretores de escola) e promover maior motivação, engajamento e participação dos alunos no processo educativo. 
O portal conta com mais de 1.300 recursos digitais pedagógicos mapeados, e os materiais ali presentes podem ser aproveitados por todas as redes de ensino do país. Professores, educadores, alunos e membros da comunidade escolar de todo o Brasil, interessados em usar a tecnologia em favor da aprendizagem têm acesso livre aos conteúdos da Plataforma Currículot, sem necessidade de registro ou de senhas de acesso (LIRA, 2014).

De acordo com Lira (2014), o material disponibilizado pela Plataforma Currículo+ é voltado, principalmente, a professores e alunos ligados às escolas estaduais paulistas, pois os conteúdos existentes na plataforma estão articulados com o currículo do Estado de São Paulo, no entanto, pela proximidade que os assuntos de ensino fundamental e médio têm nas diversas redes de ensino do país, educadores de outros Estados encontram recursos que podem ser utilizados dentro ou fora do ambiente escolar.

O Projeto Aventura Currículo+, implantado em 2015 pela Resolução SE do Estado de São Paulo no 11, de 17 de março de 2015, consiste em uma ação de recuperação contínua da aprendizagem em 10 semanas (20 aulas de 50 minutos cada), para alunos dos anos finais do ensino fundamental e do ensino médio, sendo trabalhadas competências e habilidades estruturantes, em língua portuguesa e matemática, de forma lúdica e interativa, utilizando recursos pedagógicos digitais e narrativa gamificada. As aulas são desenvolvidas com conteúdos digitais, tornando o processo de ensino e de aprendizagem mais lúdico e interativo.

O curso tem formato auto instrucional, formado por vídeos, textos e comunidade de aprendizagem para troca e interação entre os professores participantes do Projeto. A implementação das atividades com os alunos fica a cargo do professor, desenvolvendo a metodologia das aulas, a seleção de atividades, assim como o acompanhamento do processo de aprendizagem do aluno, identificando as habilidades apropriadas, nas diferentes etapas do Projeto. Os professores que ministram as aulas do Aventura Currículo+ são especialistas em matemática ou língua portuguesa. Segundo Kleine e Nacarato (2016), no primeiro ano de implantação do programa, os professores não tiveram acesso à totalidade do software utilizado nas dez semanas de curso. Eles tiveram acesso à etapa a ser trabalhada com os alunos somente na semana anterior à aplicação da atividade, assim, não tiveram uma visão geral do objeto de aprendizagem a ser trabalhado, comprometendo sua visão da totalidade do projeto e das atividades. A autora ainda observa que só houve uma edição do Aventura Currículo+ e se houver uma nova edição do Projeto deve-se antes considerar se os professores que vierem a assumir o projeto terão tempo disponível para serem reencaminhados às aulas e, inclusive, 
se a rede estadual de educação aproveitará os professores que já foram capacitados.

A Plataforma GeekieLab+, lançada em 2015, pela Secretaria de Educação, disponibiliza para estudantes um simulado on-line e gratuito, oferecido em parceria com a empresa Geekie. A finalidade é auxiliar o aluno, de forma personalizada, na preparação para o Exame Nacional do Ensino Médio (ENEM). O aluno do 3o ano do ensino médio pode utilizar a plataforma dentro e fora da escola, testar seus conhecimentos e, a partir daí acessar um plano de estudo feito especialmente para ele. Ao entrar na plataforma, o aluno faz uma avaliação diagnóstica para identificar suas dificuldades e o domínio em diferentes assuntos. Após a avaliação diagnóstica, o aluno tem acesso a um plano de estudos personalizado com base nas suas dificuldades e pode estudar em aulas disponíveis na própria plataforma. Os professores e diretores de escola que auxiliam e orientam os alunos têm material para formação disponível na plataforma, buscando integrar os estudos on-line e os estudos presenciais, podendo acompanhar o desempenho de seus alunos por meio de relatórios disponíveis na plataforma GeekieLab+. No ano de 2016, a plataforma GeekieLab+ não foi utilizada pela rede estadual de ensino do Estado de São Paulo.

Portanto, o Estado de São Paulo, buscando se adequar aos novos tempos, criou uma série de ações e programas de incentivo as TICs. A quantidade de programas é significativa e nem sempre as ações são contínuas. Apesar desse conjunto de ações, a tendência é que as políticas estaduais sejam redefinidas a partir de novos marcos regulatórios, sem grandes preocupações com os fundamentos sociais. É preciso considerar ainda as implicações do desmonte das políticas sociais, a exemplo da Emenda à Constituição 55 de 2016, que estabelece um teto para os gastos públicos pelos próximos vinte anos, definido pela inflação do ano anterior (AMARAL, 2016). A limitação de gastos impossibilitará o cumprimento das metas estabelecidas no PNE, entre elas, especialmente, a efetivação da educação obrigatória para todos os jovens entre 4 e 17 anos e a valorização do magistério da educação básica como política obrigatória em todo o território nacional, assim como a política de incentivo ao uso das TICs nas escolas públicas. 


\section{As concepções dos diretores e professores das escolas estaduais paulistas}

A pesquisa foi realizada em três escolas pertencentes à rede estadual numa cidade do interior do Estado de São Paulo. O município de realização da investigação conta com uma população de aproximadamente 84.000 habitantes e apresenta 26 escolas municipais, 11 escolas estaduais e 27 escolas particulares. Das três escolas selecionadas, aqui denominadas escola A; escola B; e escola C, duas delas estão localizadas em bairros da periferia da cidade e uma no centro. Todas as escolas oferecem o ensino fundamental II (60 ao 9o ano) e ensino médio e foram selecionadas de acordo com os seguintes critérios: localização, maior número de alunos e professores e aceite do diretor de escola em participar da pesquisa. A escola A é urbana e periférica e oferece as séries finais do ensino fundamental (6ㅇ ao 9 ano) e ensino médio, na qual funcionam três turnos - manhã, tarde e noite com aproximadamente 420 alunos e aproximadamente 44 professores; a escola B é urbana e central e oferece as séries finais do ensino fundamental (6 ao 9o ano) e ensino médio, na qual funcionam dois turnos - manhã e tarde - com aproximadamente 720 alunos e aproximadamente 46 professores; e a escola $C$ é urbana e periférica e oferece as séries finais do ensino fundamental ( 60 ao 9o ano) e ensino médio, na qual funcionam dois turnos - manhã e tarde - com aproximadamente 420 alunos e aproximadamente 30 professores.

A seleção dos sujeitos da pesquisa contou com 1 (um) diretor de escola e 3 professores de cada escola, totalizando 12 pessoas participantes que, por meio de entrevistas semi-estruturadas, prestaram depoimentos acerca da política estadual no Estado de São Paulo de incentivo as TICs, do uso das TICs em suas práticas educacionais, das ações e programas em suas escolas que incentivam as TICs, da infraestrutura na escola e formação dos profissionais para trabalhar com as TICs. A escolha dos participantes teve como critério a inclusão de professores de diferentes campos do saber e aceite em participar voluntariamente da pesquisa. Os depoimentos coletados foram submetidos à análise de conteúdo, que conforme Minayo (2007) permite descobrir os núcleos de sentidos e favorece a captação da representação social dos entrevistados. De modo geral, os núcleos de sentidos consistem num processo de redução do texto às palavras e expressões significativas e, na sequência, o pesquisador realiza inferências e interpretações considerando o quadro teórico de referência. $A$ investigação permitiu traçar um perfil aproximado dos professores e diretores escolares. Em relação à formação profissional, verificou-se que todos os diretores possuem formação superior em Pedagogia. E, em relação à formação dos professores destacam-se que dois professores são de Matemática; 3 de 
Letras; 1 (um) de História; 1 (um) de Geografia; 1 (um) de Química; e, 1 (um) de Biologia.

De modo geral, todos os professores e diretores das escolas consideram importante o uso das TICS no processo educacional. Dentre os argumentos mostram que as TICs produzem interesse e atenção dos alunos; e, enriquecem o conteúdo trabalhado ao contribuírem para ilustrar tal conteúdo. Os professores relataram que usam data-show, rádio, televisão, vídeo e a sala de informática. No entanto, em relação aos programas do governo do Estado de São Paulo, há um baixíssimo uso nas suas práticas pedagógicas e ferramentas tecnológicas; dos nove professores entrevistados, apenas dois utilizam a GeekieLab+ e o Currículo+.

O uso frequente das práticas pedagógicas e ferramentas tecnológicas não se realiza em decorrência de várias dificuldades que envolvem as condições de trabalho e de formação. Dentre as dificuldades relacionadas às condições de trabalho sobressaiu a falta de tempo necessário para preparar as aulas. Os professores, ao se referirem ao uso do data-show, por exemplo, mencionam que há necessidade de um tempo maior para preparar as aulas e eles nem sempre dispõem desse tempo já que trabalham em vários turnos:

Eu acho assim, a dificuldade maior é a gente ter o tempo para a gente estar preparando tudo isso e com a quantidade de escolas que temos hoje é muito complicado ter o tempo para o planejamento adequado. Sem contar que temos que preparar a sala antes também para poder levar o aluno. Então eu acho que a barreira um pouquinho maior que a gente encontra é essa._Mas a partir do momento que você consegue se sentar, planejar tudo aquilo que você quer, aí fica fácil, porque você agenda depois o uso da sala de informática na escola, aí não tem como, é fácil. [...] Mas o maior entrave que eu acho é o tempo de a gente planejar, temos que planejar em casa. Havia_o responsável pelo Acessa. Este ano, por enquanto, está sem. Então o professor mesmo pega e leva. Outra coisa que atrapalha muito também é o número pequeno de computadores que funcionam, não existe manutenção por parte do governo, mas quando dá a escola manda arrumar. Fica caro e a velocidade da sala de informática que é muito baixa (PROFESSOR E, ESCOLA B).

Cabe destacar que todos os professores apontam diversas dificuldades que impedem o uso das TICS no processo educacional, tais como a falta de apoio e auxílio técnico durante as aulas, o pequeno número de computadores nas escolas e a baixa velocidade de conexão:

Não existe mais o responsável pela sala de informática. Isso dificultou o trabalho do professor, porque ele está lá, ele é o responsável. Qualquer coisa que dá errado, a responsabilidade é dele. Outra dificuldade que temos é o número de alunos e o número de computadores da sala, não há computador 
pra todo mundo. Para usar o data show, levo meu computador para facilitar. [...] O professor, ele sente certa dificuldade, pela responsabilidade que ele tem. Equipamento que acaba sendo danificado, mouse etc. Controle remoto que desaparece. Então é uma responsabilidade muito grande. A gente acaba tendo muita dificuldade (PROFESSOR A, ESCOLA A).

Temos uma infraestrutura bem precária. Na sala de informática, não temos um computador para cada aluno. Além de não ter uma velocidade boa para conexão, cai muito. Algumas escolas até têm um pouco mais. A gente agenda, coloca o plano que a gente vai trabalhar, demora, mas tem jeito sim. Olha, deve haver uns doze aqui funcionando. A gente coloca em grupos para trabalhar. Um pouco, porque são vários alunos num computador só, mas conversando com eles, organizando bem, dá para ser feito um trabalho. Não é como a gente sonha, mas dá. Acho que vindo mais verba para as condições da escola, vendo a necessidade da escola, com mais computadores. Hoje você não tem como fugir disso daí, mas no momento em que a gente está vivendo, temos que aguardar um pouquinho mais (PROFESSOR C, ESCOLA A).

A escola não conta com uma infraestrutura necessária para a inserção das tecnologias nas nossas aulas. O laboratório de informática não fica mais aberto para os alunos fazerem trabalhos, pois neste ano o monitor que ficava na sala foi demitido pela Secretaria de Estado. [...] Eu acho também que a quantidade de computadores não é suficiente, porque, dependendo da sala de aula, que é numerosa, temos que ter três alunos para cada computador $\mathrm{e}$ eu acho que isso dificulta um pouco, levo até meu notebook para facilitar (PROFESSOR D, ESCOLA B).

Os diretores também concordam com os professores com o fato de que as condições necessárias para o uso das TICs nas escolas não são favoráveis:

Em relação à infraestrutura, a gente não tem uma qualidade de velocidade de internet, os equipamentos estão um tanto defasados, eles precisam ser trocados constantemente, ou mesmo, reparados constantemente. E a gente sabe da luta cada vez que quebra um aparelho, você tem que abrir a chamada, até chegar isso pra nós, é muito difícil. Então há esses empecilhos das ferramentas que estão sempre quebradas, com defasagem de tecnologias. Por medidas até de economia, planejamento financeiro da Secretaria de Educação, nós não temos mais estagiários no Acessa Escola. Isso dificultou bastante o trabalho. No momento, nós temos quinze máquinas na sala de informática, mas em funcionamento, umas onze. Então, estamos constantemente com pedidos abertos para FDE vir arrumar os computadores. Apesar de tudo, os professores utilizam a sala e os equipamentos que temos (DIRETOR, ESCOLA A).

Portanto, a dura realidade das escolas estaduais, a deficiência ou a falta de infraestrutura e disponibilidade de mão de obra técnica qualificada necessária interfere diretamente no trabalho 
docente e, consequentemente, na qualidade do uso correto e frequente das tecnologias de informação e comunicação nas escolas. Apesar da quantidade de programas que preconizam o uso das TICs como políticas públicas e educacionais no Estado de São Paulo, há falta de condições básicas, anterior ainda a qualquer infraestrutura necessária, como a conexão à internet, disponibilidade dos equipamentos etc. que interferem diretamente na adesão aos programas de inserção efetiva das TICs.

Em relação ao aspecto da formação para o uso das TIC, os professores assinalam que falta uma formação consistente e contínua nas escolas. Na verdade não há quase nenhum tipo de formação docente de qualquer tipo, muito menos a formação tecnológica, além do mais os momentos de aula de Trabalho Pedagógico Coletivo (ATPC) não são suficientes e nem o momento adequado para se preparar o professor para compreender e lidar com as TICs.

Olha, aqui na escola não existe nenhuma formação. Eu nunca fiz. Aliás na sala de informática antes tinha uma pessoa que nos auxiliava, agora não tem ninguém. Temos que resolver tudo sozinho. Sempre que preciso, algum aluno me ajuda. Mas tudo que preciso tenho que pesquisar e estudar em casa sozinho. Se houvesse um curso da Secretaria ou alguém seria muito melhor. (PROFESSOR A, ESCOLA A).

A nossa coordenadora faz isso, ajuda, auxilia todo mundo que precisa, ela é muito prestativa. Então não temos problema, ela vai lá e explica, auxilia, sem problemas. É essa formação que temos e, às vezes, o ATPC acontece na sala de informática quando temos que digitar notas ou dados. Mas a coordenadora auxilia todos os professores. Não existe uma formação mais intensa, nunca participei. Se existisse uma formação, com certeza auxiliaria muito a todos nós. Penso que o governo realmente não quer que utilizemos os programas, pois não temos formação e nem estrutura (PROFESSOR B, ESCOLA A).

A única formação que temos aqui na escola é a coordenadora que faz. A coordenação, quando necessário, vai ajudar, vai orientar. Mas de formação assim, completa, eu nunca cheguei a participar não, e se já houve, não me recordo. Tudo o que fazemos nós é que vamos buscar, estudar em casa, ou procurar alguém para nos ajudar. Algum filho ou colega que saiba mais que a gente, por isso, muitas vezes, não usamos os programas que existem. Seria muito bom se a Secretaria oferecesse cursos específicos para os programas existentes (PROFESSOR H, ESCOLA C).

Em geral, o conhecimento que os professores possuem acerca do uso das TICs no processo educacional é decorrente de esforço e interesse próprio, em um aprendizado no espaço cotidiano e informal de suas vidas pessoais e conforme as necessidades da própria vida social em que estão inseridos, não são, portanto, conhecimentos suficientemente didático-pedagógicos para qualificar 
profissionalmente o docente para esta prática. Há que ressaltar que as coordenadoras de escola promovem ações de formação e incentivo ao uso das TICs, mas tudo indica que as ações são pontuais e informais, como dicas e receitas em relação ao preparo dos professores para o uso prático ou manual das TICs. Não há propriamente uma formação profissional em TICs, muito menos com os processos de ensino-aprendizagem.

\begin{abstract}
Com relação à formação, veio um pessoal da Diretoria que cuida dessa parte e mostrou todo o processo para os professores de como utilizar a sala de informática. [...] Faz uns dois anos. Os professores tiveram aula prática com esse pessoal. Cada um ficou no computador e ela foi falando: "olha pessoal, entra aqui", "faz isso". Então eles tiveram uma aula prática para depois eles poderem usar com os alunos. [...] Era para utilizar com algum programa da secretaria, acho que era A Plataforma Currículot. A coordenadora estava junto, mas depois disso, não aconteceu mais, então ela ocorre, mas poderia ser melhor [...]. Sim, nosso ATPC é de formação. Minha coordenadora fez também o curso, então nessa parte ela é bem dinâmica, ela entende bem. Então ela traz para os professores: Ela desenvolve bastante esse lado. Ela passa nos ATPC, sabe? Ela vai à sala de computação junto com professores e ajuda no que for preciso (DIRETOR, ESCOLA C).
\end{abstract}

Os depoimentos indicam que a simples implementação de leis, programas e ações não garantem nem mesmo a simples utilização corriqueira das TICs no processo educacional. Há sérios limites de formação, qualificação e capacitação que acompanham as contradições da política de educação via TICS, mesmo quando se pretende afirmar que a política é de fato de incentivo ao uso das TICs no processo educacional. Há de destacar que a formação de professores para o uso das TICs não pode ser algo pontual, negligenciado e/ou a cargo dos próprios professores, diretores ou especialistas, como de suas responsabilidades individuais e pessoais. A qualificação não é algo pessoal, mas uma política cuja responsabilidade é institucional e governamental. A formação para o uso das TICs, não deve se restringir igualmente ao simples "uso", deve permear uma nova concepção de formação, não apenas como ferramenta mediadora, mas como concepção educacional e social integradas entre si, como entidade própria do ambiente escolar e como reflexo direito da própria modernidade em que a tecnologia permeia a vida social. Daí, portanto, não se tratar, também, apenas de ferramenta. Por conseguinte, o simples acesso à tecnologia em si não parece ser o aspecto mais importante, mas as condições de formação e de infraestrutura parecem determinar o êxito da "política de incentivo" à utilização das TICs nos processos educacionais. 


\section{Considerações Finais}

Este artigo tratou da percepção de diretores e professores acerca das políticas de incentivo ao uso das TICs nas escolas estaduais do Estado de São Paulo. De modo geral, as TICs adquirem importância na legislação educacional a partir de meados da década de 1990, com destaque na LDB de 1996 e, mais recentemente, nas Diretrizes Curriculares de 2013 e no PNE de 2014. No arcabouço legal é evidente o interesse em utilizar as TICs na melhoria do nível de aprendizado ao longo da escolarização e na formação de professores. E, que a aspiração é produzir uma nova racionalidade educacional nas quais as TICs assumem o critério objetivo de aferimento da qualidade da educação.

Observou-se, na nova racionalidade de incentivo ao uso das TICs na educação, que vários programas direcionados ao seu uso foram criados pelo governo estadual do Estado de São Paulo. Apesar da grande quantidade de programas, a política educacional baseada na criação de vários programas não parece consistente. Cabe mencionar a falta de continuidade nas ações, problemas de formação e de recursos materiais e humanos. Os diretores e professores são unânimes em considerar a importância das TICs no processo educacional, no entanto, chamam a atenção aos sérios problemas enfrentados nas escolas em relação às condições de infraestrutura e de formação de professores para o "uso" das TICs.

O estudo constatou a necessidade de descortinar as reais intenções governamentais e as contradições de uma política pública que cria inúmeros programas de incentivo às TICs sem assegurar as condições concretas para sua materialização. Diante disso, tornam-se cruciais estudos que procedam a uma análise de cunho político e econômico de inserção das TICs nas políticas educacionais.

\section{Referências}

ALMEIDA, M. E. B.; VALENTE, J. A. Integração currículo e tecnologias e a produção de narrativas digitais. Currículo sem Fronteiras, v. 12, n. 3, p. 57-82, set/dez, 2012. Disponível em: $<$ http://www.curriculosemfronteiras.org/vol12iss3articles/almeida-valente.pdf>. Acesso em: 22 set. 2016.

AMARAL, N. C. PEC 241/55: a "morte" do PNE (2014-2024) e o poder de diminuição dos recursos educacionais. Revista Brasileira de Política e Administração Escolar. v. 32, n. 3, p. 653-673, set./dez., 2016. Disponível em: <http://seer.ufrgs.br/index.php/rbpae/article/view/70262>. Acesso em: 22 set. 2016.

BRASIL. Lei no. 9.394, de 20 de dezembro de 1996. Estabelece as diretrizes e bases da educação nacional. Diário Oficial da União, Brasília, DF, 23 dez. 1996. 
. Ministério da Educação e do Desporto. Portaria n. 522/MEC, de 9 de abril de 1997. Cria o Programa Nacional de Tecnologia Educacional - Prolnfo. Brasília, DF: MEC, 1997. Disponível em: $<$ https://www.fnde.gov.br/fndelegis/action/UrlPublicasAction.php?acao=getAtoPublico\&sgl_tipo=PO R\&num_ato $=00000522 \&$ seq_ato=000\&vlr_ano=1997\&sgl_orgao=MED>. Acesso em: 26 set. 2016.

Presidência da República. Casa Civil. Subchefia para Assuntos Jurídicos. Decreto n. 6.300, de 12 de dezembro de 2007. Dispõe sobre o Programa Nacional de Tecnologia Educacional - Prolnfo. Brasília, DF: MEC, 2007. Disponível em: <http://www.planalto.gov.br/ccivil 03/ ato20072010/2007/decreto/d6300.htm>. Acesso em: 26 set. 2016.

Ministério da Educação. Construindo o sistema nacional articulado de educação: o Plano Nacional de Educação, diretrizes e estratégias de ação. Documento final da CONAE 2010. Brasília, DF: MEC 2010. Disponível

em: $<$ http://conae.mec.gov.br/images/stories/pdf/pdf/documetos/documento_final.pdf $>$. Acesso em: 20 jan. 2016.

Ministério da Educação. Secretaria de educação Básica. Diretrizes Curriculares Nacionais Gerais da Educação Básica. Brasília, DF: MEC, SEB, DICEI, 2013. Disponível em: <http://portal.mec.gov.br/docman/julho-2013-pdf/13677-diretrizes-educacao-basica-2013-pdf/file>. Acesso em: 26 set. 2016.

Ministério da Educação. Conferência Nacional de Educação: documento - referência / [elaborado pelo] Fórum Nacional de Educação - Brasília, DF: MEC, 2013. Disponível em: <http://conae2014.mec.gov.br/images/pdf/doc referencia.pdf $>$. Acesso em: 26 set. 2016.

Ministério da Educação. Lei n. 13.005, de 25 de junho de 2014. Aprova o Plano Nacional de Educação - PNE e dá outras providências. Diário Oficial da União (República Federativa do Brasil), Brasília, DF: Seção 1, Edição Extra, 26 jun. 2014, p. 1. Disponível em: <http://www2.camara.leg.br/legin/fed/lei/2014/lei-13005-25-junho-2014-778970publicacaooriginal-144468-pl.html>. Acesso em: 27 set. 2016.

. Constituição (1988). Proposta de Emenda à Constituição n 55 , de dezembro de 2016. Altera o ato das Disposições Constitucionais Transitórias para instituir o novo Regime Fiscal. Disponível em: <https://www25.senado.leg.br/web/atividade/materias/-/materia/127337>. Acesso em: 20 de abr. 2017.

BONILLA, M. H. S.; PRETTO, N. L. Inclusão digital: polêmica contemporânea. Salvador: EDUFBA, 2011.

CARVALHO, A. C. Atribuições do Núcleo de Informações Educacionais e Tecnologia. Disponível em: $<$ http://desjbarra.educacao.sp.gov.br/Paginas/Institucional/N\%C3\%BAcleo-deInforma\%C3\%A7\%C3\%B5es-Educacionais-e-Tecnologias.aspx>. Acesso em: 11 dez. 2016.

CARVALHO, J. S. F. "Democratização do ensino" revisitado. Educação e Pesquisa, São Paulo, v. 30, n. 2, p. 327-334, mai/ago. 2004. Disponível em: <http://www.scielo.br/pdf/ep/v30n2/v30n2a11.pdf>. Acesso em: 11 dez. 2016.

CASTELLS, M. A sociedade em rede - a era da informação: economia, sociedade e cultura. São Paulo: Paz e Terra, 1999. 
DOURADO, L. F.; OLIVEIRA, J. F. A qualidade da educação: perspectivas e desafios. Cadernos Cedes, Campinas, v. 29, n. 78 , p. 201-2015, mai/ago. 2009. Disponível em: <http://www.scielo.br/pdf/ccedes/v29n78/v29n78a04.pdf >. Acesso em: 11 dez. de 2016.

KLEINE, M. R.; NACARATO, A. M. Aventura currículo+ e a formação do professor de matemática: um estudo de caso. In: 14ạ Jornada do Núcleo de Ensino de Marília. Marília: Unesp, 2015. v. 1. p. 1-14.

LIRA, D. Plataforma Currículo + oferece recursos digitais a professores de todo o país. 2014. Disponível em: <http://ultimosegundo.ig.com.br/educacao/2014-05-27/governo-de-sp-lanca-portalque-aproxima-recursos-digitais-de-professores-do-pais.html>. Acesso em: 26 set. 2016.

MAGNONI, A. F.; SILVA, S. R. O desafio da interação no ensino de língua estrangeira em cursos on-line e presenciais nas escolas públicas paulistas. Revista Educação e Linguagens. Campo Mourão, v. 3, n. 5, jul./dez. 2014.2 Disponível em: <http://www.fecilcam.br/revista/index.php/educacaoelinguagens/article/view/671/406>. Acesso em: 26 set. 2016.

MINAYO, M. C. S. O desafio do conhecimento: pesquisa qualitativa em saúde. 10. ed. São Paulo: HUCITEC, 2007.

MONTEIRO, A. M. A. Acessa Escola: sua utilização na prática docente. 2015. 163f. Dissertação. Mestrado (Desenvolvimento Humano: Formação, Políticas e Práticas Sociais) - Universidade de Taubaté, Taubaté- SP, 2015.

PONTE, J. P Tecnologias de informação e comunicação na formação de professores: que desafios? Revista Iberoamericana de Educación. Madrid, n. 24, p. 63-90, sep./dec., 2000. Disponível em: <http://repositorio.ul.pt/handle/10451/3993>. Acesso: em 26 set. 2016.

SÃO PAULO. Currículo Mais. Disponível em: <http://curriculomais.educacao.sp.gov.br>. Acesso: em 14 set. 2016.

. Secretaria da Educação do Estado de São Paulo. Resolução do Estado de São Paulo SE no 37, de 25 de abril de 2008. Institui o Programa Acessa Escola para atendimento aos alunos, professores e servidores das Escolas da Rede Estadual de Ensino. Disponível em: $<$ http://siau.edunet.sp.gov.br/ItemLise/arquivos/37 08.HTM?Time=15/10/2017\%2020:46:27>. Acesso em: 26 set. 2016.

. Secretaria da Educação do Estado de São Paulo. Decreto no 57.011, de 23 de maio de 2011. Cria a Escola Virtual de Programas Educacionais do Estado de São Paulo - EVESP, e dá providências correlatas. Disponível em: <http://www.al.sp.gov.br/repositorio/legislacao/decreto/2011/decreto57011-23.05.2011.html>. Acesso em 26 set. 2016.

. Secretaria da Educação do Estado de São Paulo. Resolução do Estado de São Paulo SE no 39, de 10-6-2011. Institui o Programa Acessa Escola para atendimento aos alunos, professores e servidores das escolas da rede estadual de ensino. Disponível em: <http://siau.edunet.sp.gov.br/ItemLise/arquivos/39 11.HTM?Time=15/10/2017\%2020:49:21>.

Acesso em: 26 set. 2016.

. Secretaria da Educação do Estado de São Paulo. Decreto no 57.141, de 18 de julho de 2011. Reorganiza a Secretaria da Educação e dá providências correlatas. Disponível em: 
<http://www.al.sp.gov.br/repositorio/legislacao/decreto/2011/decreto-57141-18.07.2011.html>. Acesso em: 26 set. 2016.

. SECRETARIA DA EDUCAÇÃO DO ESTADO DE SÃO PAULO. Escola Virtual de Programas educacionais. 2013. Disponível em <http://www.educacao.sp.gov.br/evesp/cursos/>. Acesso em: 28 out. 2016.

. Secretaria da Educação do Estado de São Paulo. Resolução SE do Estado de São Paulo no 11, de 17 de março de 2015. Institui o Projeto Aventuras Currículo+ nas escolas da rede estadual de ensino e dá providências correlatas. Disponível em: <http://siau.edunet.sp.gov.br/ItemLise/arquivos/11 15.HTM?Time=15/10/2017\%2020:57:16>. Acesso em: 26 set. 2016.

ROSA, R. Trabalho docente: dificuldades apontadas pelos professores no uso das tecnologias. Revistas UNIUBE. Uberaba, MG. v. 1, n. 1, 2013. Disponível em <http://revistas.uniube.br/index.php/anais/article/view/710> Acesso em: 26 de 2016.

ZUIN, A. A. S. O plano nacional de educação e as tecnologias da informação e comunicação. Educação \& Sociedade, Campinas, v. 31, n. 112, p. 961-980, jul/set, 2010. Disponível em: <http://www.cedes.unicamp.br>. Acesso: em 20 out. 2016. 